\title{
PRÓLOGO
}

\section{La investigación geográfica del turismo}

\author{
Xosé SOMOZA MEDINA (somoza@unileon.es) \\ Departamento de Geografía y Geología de la Universidad de León
}

Este número de Poligonos. Revista de Geografía, tiene su origen en una selección de las ponencias e investigaciones presentadas en el XVI Coloquio de Geografía del Turismo, Ocio y Recreación de la Asociación de Geógrafos Españoles, celebrado en la Universidad de León, del 27 al 29 de septiembre de 2018. Una vez terminado la reunión, y como editor académico de este número, le solicité a los autores que ampliaran sus aportaciones para poder formar parte de este monográfico. Los contenidos aquí expuestos reflejan la vitalidad y trascendencia de los estudios geográficos sobre el turismo, con aportaciones que analizan destinos litorales, urbanos, rurales o de naturaleza, no sólo de España, sino también de otros países del mundo. Esta circunstancia, que a un Coloquio de la Asociación de Geógrafos Españoles se presentara un número considerable de aportaciones extranjeras demuestra dos hechos incontestables, primero, el carácter internacional del turismo y de las investigaciones sobre este fenómeno social, y segundo, la posición de España como un país de referencia mundial en relación al turismo, además de por las conocidas magnitudes de las actividades turísticas que se desarrollan dentro de sus fronteras, por la calidad académica e impacto mediático de las autoras y autores que lideran la investigación turística española.

Los artículos que componen este monográfico se inician con un trabajo teórico del profesor Rubén C. Lois González, de la Universidad de Santiago de Compostela, en el que expone de forma bien jerarquizada la posición del turismo dentro de la estructura competencial de la administración del territorio y los problemas que surgen entre la lentitud de los procesos burocráticos y el dinamismo acelerado de esta actividad. A continuación, la arquitecta Marta Somoza Medina presenta una experiencia práctica y personal que explica como desde unos talleres de educación creativa con niñas y niños se pueden trabajar conceptos tan abstractos, complejos e interesantes como el paisaje, la ciudad, la movilidad, la atmósfera o 
la identidad, y reinterpretarlos en clave de turismo doméstico. El tercer artículo, escrito por el profesor italiano Enrico Nicosia, nos introduce la importancia de las series de televisión en la creación de imágenes turísticas, estudiando el caso de Sicilia y la serie El Comisario Montalbano. La importancia de las imágenes y de lo que se pretende transmitir con ellas es también el nudo central del siguiente artículo, escrito por Mireia Zapata Andreu, en el que con perspectiva de género investiga el papel de la mujer en las representaciones de los centros expositivos de turismo industrial (colonias) de Cataluña. A continuación, Stefania Pareti Petruccelli, Blanca García Henche y Erica Salvaj Carrera muestran la importancia de las redes de colaboración y asociacionismo en la dinamización de sectores tradicionales de la ciudad que se convierten en barrios turísticos con nuevas oportunidades de desarrollo, ejemplificando el análisis en los barrios de las Letras de Madrid e Italiano de Santiago de Chile. Luis Alfonso Escudero Gómez, de la Universidad de Castilla-La Mancha, expone en el artículo siguiente las características peculiares de un viaje turístico masivo y recurrente, el que organizan diferentes empresas para conocer la ciudad de Toledo desde Madrid, con la intención de recorrer la ciudad imperial en unas pocas horas, como si se tratara de la visita a unos estudios cinematográficos. Los problemas de saturación y concentración turística señalados en este artículo, son también el argumento fundamental del trabajo que presentan, sobre la ciudad de Madrid, Manuel de la Calle Vaquero, Elena Ferreiro Calzada y Sofía Mendoza de Miguel. En él se muestra un catálogo de medidas desarrolladas en diferentes destinos para tratar de solucionar estos problemas y también las principales actuaciones contenidas en los planes estratégicos de Madrid (2011-2015 y 2015-2019). Otro ejemplo de planificación y gestión turística de un destino urbano es el que presenta a continuación Raquel Berzosa Pareja, en este caso analizando el proceso de realización e implementación del Plan de Excelencia Turística de Salamanca. El siguiente artículo de este número monográfico se corresponde con el trabajo que firman Francesc López Palomeque, Anna Torres-Delgado, Berezi Elorrieta Sanz, Xavier Font Urgell y Damià Serrano Miracle sobre el uso de indicadores para la gestión sostenible de destinos turísticos en la provincia de Barcelona, en el que nos cuentan su experiencia práctica en la elaboración y seguimiento de una herramienta de gestión turística aplicada por la Diputación de Barcelona. Sostenibilidad, criterios e indicadores es también la base del siguiente artículo de Adrián Ferrandis Martínez, Sandra J. Schubert y Cristina García Cardona de la Universidad de Valencia, en este caso en relación al turismo desarrollado en espacios naturales protegidos. A continuación se expone el trabajo enviado por la profesora María de J. Santiago Cruz sobre ecoturismo y desarrollo local, con un análisis detallado sobre dos ejemplos en el sureste mexicano. El siguiente artículo, de Yamilé Pérez Guilarte, Iago Lestegás y Francisco Xosé Armas Quintá, expone una herramienta 
concreta de gestión turística en un territorio fronterizo y mayoritariamente rural, la eurorregión Galicia-Norte de Portugal, a través de un sistema interactivo de información georreferenciada de los recursos patrimoniales. Finalmente, el último artículo, firmado por Raúl Molina Otárola, muestra una interesante experiencia de gestión indígena, no exenta de distintas problemáticas, en dos destinos cargados de simbología, el desierto de Atacama y Rapa Nui.

Estos artículos representan una selección de las casi 50 aportaciones que se expusieron en el XVI Coloquio de Geografía del Turismo, Ocio y Recreación de la Asociación de Geógrafos Españoles. Como se puede observar en el índice de este número monográfico, la variedad temática de las investigaciones reflejan la complejidad del fenómeno turístico. Una complejidad que se ha incrementado de manera exponencial en las últimas décadas, con la imposición de lo que podríamos denominar el turismo global, que convierte cualquier lugar del planeta en un destino turístico potencial, incrementando de forma colateral el interés de la Geografía por su estudio. El turismo como disciplina académica se caracteriza por su interdisciplinariedad. Son muchas las ciencias sociales que lo investigan desde sus particulares puntos de vista; la economía como mercado de oferta y demanda, la sociología y antropología a través de los impactos en la sociedad emisora y receptora, la psicología por la relación entre el individuo y las prácticas turísticas, o la historia, analizando la evolución del turismo en el tiempo. La Geografía, como demostró este coloquio, se preocupa fundamentalmente del análisis de los procesos de cambio que el turismo genera en los destinos. Por ello decimos que el interés de la Geografía por el turismo se ha incrementado en los últimos años, desde preocupar de manera específica a los investigadores de Geografía económica o de los servicios, a aparecer como tema de estudio en muchas subdisciplinas de la Geografía Humana y Regional, pues todo lugar puede convertirse en destino.

El XVI Coloquio de Geografía del Turismo, Ocio y Recreación de la AGE tuvo como título "Teorías, modelos y destinos turísticos en épocas de cambios", tratando de incentivar la presentación de comunicaciones que abordaran un desarrollo teórico y metodológico en el ámbito académico español. Un objetivo alcanzado mínimamente pero que podemos justificar como un error de partida, por excesivamente pretencioso, cuando el objetivo de los coloquios es presentar la investigación que se realiza en ese momento, de forma individual o en grupos, en el mundo académico. Y esta investigación está condicionada, como también observamos en los epígrafes de muchas de las comunicaciones presentadas, por las temáticas específicas de las convocatorias de subvenciones públicas, que no suelen financiar desarrollos teóricos o metodológicos, y si estudios de casos concretos en el ámbito de las administraciones convocantes. 
Las investigaciones que recoge este número de Polígonos. Revista de Geografia, realizadas por profesionales y académicos de España y otros países, muestran con abundantes ejemplos la complejidad de los estudios sobre el turismo. Las temáticas son variadas y los enfoques de análisis también. El turismo comprende una amplia gama de actividades y actores que deben ser estudiados de forma multidisciplinar por diversas ciencias sociales, pero la lectura de estos artículos justifica el papel fundamental en el análisis del turismo de la ciencia geográfica. La transformación de un lugar geográfico en destino turístico genera una serie de procesos de cambio de tipología diversa: espaciales, sociales, económicos, culturales, que son analizados con fundamentación teórica y metodológica por la Geografía. Las geógrafas y geógrafos somos los científicos de los lugares y por ello es crucial el papel de esta ciencia en el estudio de una actividad social tan estrechamente ligada a las características particulares del territorio como es el turismo.

Otra conclusión que pudimos extraer del XVI Coloquio es el carácter internacional y transfronterizo de los estudios turísticos. El turismo genera diariamente millones de desplazamientos de personas, bienes y capitales que cruzan fronteras y llegan a cualquier rincón del planeta. Como decíamos antes, cualquier lugar es susceptible de convertirse en destino turístico, y cualquier destino turístico pretende su internacionalización. Esta circunstancia se traslada al estudio sobre el turismo y las personas que investigamos este fenómeno social somos conscientes de su mundialización. Incluso formamos parte de ella, dedicando buena parte de nuestras vidas a viajar, conocer y documentar destinos turísticos por todo el mundo, que después pueden convertirse en objeto de análisis en una investigación académica.

La lectura de los diferentes artículos incluidos en este número monográfico también nos permite destacar otro concepto que se repite en numerosas ocasiones, tanto en los contenidos como en los propios títulos, la sostenibilidad. Las geógrafas y geógrafos somos especialmente sensibles en este aspecto y normalmente asociamos desarrollo turístico y sostenibilidad. Esta circunstancia particular confiere un nuevo valor añadido a la Geografía en relación al turismo, frente a otras ciencias sociales. Y no únicamente a la hora de realizar estudios sobre un destino particular o un determinado tipo de turismo, sino especialmente en la capacidad de planificación y gestión sostenible del turismo.

Para terminar me gustaría realizar tres observaciones finales, a manera de grandes objetivos a cumplir en el corto y medio plazo. En primer lugar, las investigaciones geográficas sobre el turismo deben trascender de los análisis locales meramente descriptivos y ofrecer a la comunidad científica investigaciones pro- 
positivas en las que la sostenibilidad sea siempre un elemento clave, además de profundizar en la fundamentación teórica y metodológica. En segundo lugar, el análisis geográfico del turismo debería promover la creación de grupos de investigación interuniversitarios entre universidades españolas y latinoamericanas. El interés por el turismo en estos países es manifiesto y alianzas estratégicas entre grupos de investigación establecidos incrementarían la relevancia de la Geografía. Finalmente, este salto de calidad debería reflejarse por parte de los distintos gobiernos en las convocatorias oficiales de subvenciones a la investigación fundamental y aplicada, así como en el incremento de la financiación privada de la investigación turística realizada desde la Geografía. 